COMENT. This comprehensive report on the infant with anencephaly provides medical information of importance in the analysis of social, legal, and ethical issues concerning transplantation of organs fram anencephalic infants.

\title{
CONGENITAL NEUROLOGIC MALFORMATIONS
}

A 17-year survey of major congenital neurologic malformations among infants born in U.S. Army Hospitals worldwide from January 1 , 1971 through December 31, 1987 is presented from the Neonatology Services, Walter Reed Amry Medical Center, Washington, DC and Travis Grant USAF Medical Center, Travis Air Force Base, CA. From a population of $763 \quad 364$ live-born and stillborn infants, 275 had anencephaly ( 0.36 per 1000 total births), 526 had spina bifida $(0.69$ per 1000), 112 had encephaloceles (0.15 per 1000), and 370 had hydrocephalus ( 0.48 per 1000 total births). The incidence of aNS defects among stillborn infants was 24 times greater than among live-born infants. There was a female preponderance of infants with anencephaly, spina bifida and encephalocele and a male predaminance for hydrocephalus. Black infants were less likely than white infants to have spina bifida. Other congenital anomalies were associated in $20 \%$ of infants with anencephaly, $40 \%$ with encephaloceles, $37 \%$ with hydrocephalus, and $22 \%$ with spina bifida. (Wiswell TE et al. Major congenital neurologic malformations. A 17-year survey. AJDC Jan $1990 ; 144: 61-67)$.

COMMENT. The racial background of the patient population in this study closely resembled that of the United States as a whole and the results may reflect those of the U.S. In the past 20 years, declines in the frequencies of anencephaly and spina bifida have been noted in many countries, particularly in the British Isles. In the present study the incidence of neural tube defects decreased only among white female infants and no etiological factor could be implicated.

\section{CEREBELLAR VERMIS AGENESIS}

The syndromes of vermal agenesis are reviewed from the Department of Pediatrics, Hopital des Enfants Malades, Paris, France. These include the Dandy-Walker syndrome and other complicated cases associated with multiple abnormalities. The Dandy-Walker syndrome consists of three abnormalities of development: 1) Partial or complete agenesis of the vermis of the cerebellum; 2) cystic formation in the posterior fossa cammunicating with the fourth ventricle; and 3 ) hydrocephalus. Enlargement of the posterior fossa and elevation of the torcular and lateral sinuses are sametimes included among the diagnostic criteria. Associated abnormalities include agenes is of the corpus callosum (7-15\% of patients), occipital encephalocele (18\%), cleft lip and palate, cardiac malformations, urinary tract abnormalities, and minor facial dysmorphisms. The prognosis is guarded, $75 \%$ having borderline IQ or lower, and a mortality rate of $27 \%$ in some series. Various chromosomal abnormalities have been demonstrated in a few patients but their significance is unclear. There is a 1-2\% chance of recurrence in the same family. Syndromes of 